\title{
LETTER TO THE EDITOR USE OF CHLOROQUINE OR HYDROXYCHLOROQUINE IN TREATMENT OF COVID-19: IS IT ETHICAL?
}

\author{
Mohamed Farouk Allam, Fady Andraous \\ Department of Family Medicine, Faculty of Medicine, Ain Shams University, Cairo, Egypt
}

Address for correspondence: M. Farouk Allam, Department of Family Medicine, Faculty of Medicine, Ain Shams University, 11566 Abbasia, Cairo, Egypt. E-mail: farouk.allam@med.asu.edu.eg

https://doi.org/10.21101/cejph.a6464

Since the Chinese health authorities declared the novel coronavirus (COVID-19) outbreak last December, 2019, several diagnosis and treatment protocols were published. Chloroquine, a known antimalarial drug, was suggested among the pilot treatments for COVID-19 (1).

A comprehensive search in PubMed from July 1966 to 1 January 2020 identified 20 publications about coronaviruses and chloroquine. Of which, 16 publications were in-vitro and in-vitro experiments and 4 were narrative reviews. The identified studies were published between 1987 and 2019. None of the recent recommendations to treat COVID-19 with chloroquine were based on randomized controlled clinical trials (RCTs). Also, the recommendations included various doses and regimens; some of which combined chloroquine or its metabolite, hydroxychloroquine, with other drugs such as azithromycin $(1,2)$.

Last April 2020, a report of the European Medicine Agency recommended chloroquine for treatment of COVID-19 only in RCTs or emergency use programmes (3). The politicization and premature use of chloroquine and hydroxychloroquine in the treatment of COVID-19 threatened the drug supply for patients who use it for chronic conditions such as systemic lupus erythematosus and rheumatoid arthritis $(4,5)$.

On 27 April 2020, Juurlink outlined the potential hazards associated with the use of chloroquine and hydroxychloroquine with azithromycin in the management of COVID-19 (6). Studies have shown that the combination of chloroquine or hydroxychloroquine with azithromycin increases the risk of QT prolongation and possibly increases mortality in COVID-19 patients (7-9). Concurrently, in the same month in Sweden, several hospitals stopped using chloroquine for treating COVID-19 after reports of several severe side effects (10).

Factors such as small sample size, lack of a control group, baseline differences between control and intervention groups and variation in drug dosage and regimens conflict the efficacy of chloroquine $(11,12)$. Despite some reported reduction in viral load and viral RNA clearance time, no trials have proven that chloroquine or its metabolites have significant clinical benefits such as reduction in morbidity, mortality and hospital stay associated with COVID-19 (9, 11, 13-15).
Most recently, the UK's Recovery Trial, the largest trial, revealed that hydroxychloroquine is not effective in the treatment of hospitalized COVID-19 patients and does not reduce mortality or morbidity $(9,11)$. On 15 June 2020, the US Food and Drug Administration (FDA) revoked the authorization for hydroxychloroquine and chloroquine emergency use, which was previously granted to the Strategic National Stockpile to treat a subset of hospitalized COVID-19 cases (16). The World Health Organization (WHO) temporarily stopped the hydroxychloroquine arm in the Solidarity trial, then later resumed it. Similarly, in the UK's large Recovery Trial the safety board noted no sign of harm to participants. The current knowledge on COVID-19 is fluent (11).

Undoubtedly, Phase II and III RCTs are needed to assess the efficacy and adverse events of the use of chloroquine or hydroxychloroquine in treating COVID-19 (17).

To date, the use of chloroquine or hydroxychloroquine in COVID-19 treatment is restricted to clinical trials. The efficacy of chloroquine or hydroxychloroquine in pre- or post-exposure prophylaxis groups is unknown and pending the outcomes of clinical trials.

This raises the following questions: is the current use of chloroquine or hydroxychloroquine, while awaiting RCTs results, ethical? Should the medical community hold off its use while the RCT results pend? Is it ethical to suggest the prophylactic use of chloroquine or hydroxychloroquine for healthcare workers?

\section{Conflicts of Interests}

None declared

\section{REFERENCES}

1. McIntosh K. Coronavirus disease 2019 (COVID-19): epidemiology, virology, and prevention [Internet]. Waltham: UpToDate; 2020 [cited 2020 Aug 8]. Available from: https://www.uptodate.com/contents/coronavirusdisease-2019-covid-19.

2. Centers for Disease Control and Prevention. Coronavirus Disease 2019 (COVID-19). Information for clinicians on investigational therapeutics for patients with COVID-19 [Internet]. Atlanta: CDC; 2020 [cited 2020 Aug 8]. Available from: https://www.cdc.gov/coronavirus/2019-ncov/ hcp/therapeutic-options.html. 
3. European Medicines Agency. COVID-19: chloroquine and hydroxychloroquine only to be used in clinical trials or emergency use programmes [Internet]. Amsterdam: European Medicines Agency; 2020 [cited 2020 Aug 8]. Available from: https://www.ema.europa.eu/en/news/covid-19chloroquine-hydroxychloroquine-only-be-used-clinical-trials-emergency-use-programmes.

4. Mendel A, Bernatsky S, Askanase A, Bae SC, Clarke AE, CostedoatChalumeau N, et al. Hydroxychloroquine shortages among patients with systemic lupus erythematosus during the COVID-19 pandemic: experience of the Systemic Lupus International Collaborating Clinics. Ann Rheum Dis. 2020 Jun 25; annrheumdis-2020-218164. doi: 10.1136/ annrheumdis-2020-218164.

5. Plüß M, Chehab G, Korsten P. Concerns and needs of patients with systemic lupus erythematosus regarding hydroxychloroquine supplies during the COVID-19 pandemic: results from a patient-centred survey. Ann Rheum Dis. 2020 Jul 2;annrheumdis-2020-217967. doi: 10.1136/ annrheumdis-2020-217967.

6. Juurlink DN. Safety considerations with chloroquine, hydroxychloroquine and azithromycin in the management of SARS-CoV-2 infection. CMAJ. 2020 Apr 27;192(17):E450-3.

7. Mercuro NJ, Yen CF, Shim DJ, Maher TR, McCoy CM, Zimetbaum PJ, et al. Risk of QT interval prolongation associated with use of hydroxychloroquine with or without concomitant azithromycin among hospitalized patients testing positive for coronavirus disease 2019 (COVID-19). JAMA Cardiol. 2020 May 1;e201834. doi: 10.1001/jamacardio.2020.1834.

8. Jankelson L, Karam G, Becker ML, Chinitz LA, Tsai MC. QT prolongation, torsades de pointes, and sudden death with short courses of chloroquine or hydroxychloroquine as used in COVID-19: A systematic review. Heart Rhythm. 2020 Sep;17(9):1472-9.

9. Randomised Evaluation of COVID-19 Therapy (RECOVERY). Statemen from the chief investigators of the Randomised Evaluation of COVid-19 thERapY (RECOVERY) Trial on hydroxychloroquine, 5 June 2020. No clinical benefit from use of hydroxychloroquine in hospitalised patients with COVID-19 [Internet]. [cited 2020 Aug 8]. Available from: https:// www.recoverytrial.net/files/hcq-recovery-statement-050620-final-002. pdf.

10. McCall R. Some Swedish hospitals have stopped using chloroquine to treat covid-19 after reports of severe side effects. Newsweek [Internet].
2020 Sep 14 [cited 2020 Aug 8]. Available from: https://www.newsweek. com/swedish-hospitals-chloroquine-covid-19-side-effects-1496368.

11. Prevention and treatment of COVID-19 with chloroquine or hydroxychloroquine [Internet]. Ottawa: Canadian Pharmacists Association; 2020 [cited 2020 Aug 8]. Available from: https://www.pharmacists.ca/cpha-ca/ assets/File/cpha-on-the-issues/CQ-HCQ-COVID-FINAL-EN.pdf.

12. Borba MGS, Val FFA, Sampaio VS, Alexandre MAA, Melo GC, Brito M, et al.; CloroCovid-19 Team. Effect of high vs low doses of chloroquine diphosphate as adjunctive therapy for patients hospitalized with severe acute respiratory syndrome coronavirus 2 (SARS-CoV-2) infection: A randomized clinical trial. JAMA Netw Open. 2020 Apr 1;3(4):e208857. doi: 10.1001/jamanetworkopen.2020.8857.

13. Gautret P, Lagier JC, Parola P, Hoang VT, Meddeb L, Mailhe M, et al. Hydroxychloroquine and azithromycin as a treatment of COVID-19: results of an open-label non-randomized clinical trial. Int J Antimicrob Agents. 2020;56(1):105949. doi:10.1016/j.ijantimicag.2020.105949.

14. Gautret P, Lagier JC, Parola P, Hoang VT, Meddeb L, Sevestre J, et al. Clinical and microbiological effect of a combination of hydroxychloroquine and azithromycin in 80 COVID-19 patients with at least a six-day follow up: A pilot observational study. Travel Med Infect Dis. 2020;34:101663. doi:10.1016/j.tmaid.2020.101663.

15. Huang M, Li M, Xiao F, Pang P, Liang J, Tang T, et al. Preliminary evidence from a multicenter prospective observational study of the safety and efficacy of chloroquine for the treatment of COVID-19. Natl Sci Rev. 2020 Sep 1;7(9):1428-36.

16. U.S. Food and Drug Administration. Coronavirus (COVID-19) update: FDA revokes emergency use authorization for chloroquine and hydroxychloroquine [Internet]. Silver Spring: FDA; 2020 [cited 2020 Aug 8] Available from: https:/www.fda.gov/news-events/press-announcements/ coronavirus-covid-19-update-fda-revokes-emergency-use-authorizationchloroquine-and.

17. ClinicalTrials.gov. Clinical studies related to COVID-19 [Internet]. [cited 2020 Aug 8]. Available from: https://clinicaltrials.gov/ct2/ results? cond=COVID-19.

Received July 1, 2020 Accepted in revised form August 11, 2020 